\title{
The Serotonin Transporter 5-HTTPR Polymorphism is associated with Current and Lifetime Depression in Persons with Chronic Psychotic Disorders
}

\author{
Javier Contreras ${ }^{\mathrm{a}, \mathrm{c}}$, Liz Hare ${ }^{\mathrm{a}}$, Beatriz Camarena ${ }^{\mathrm{e}}$, David Glahn $^{\mathrm{a}}$, Albana Dassori ${ }^{\mathrm{a}}$, Rolando \\ Medina $^{\mathrm{a}}$, Salvador Contrerasa, Mercedes Ramirez ${ }^{\mathrm{a}}$, Regina Armas ${ }^{\mathrm{g}}$, Rodrigo Munoz ${ }^{\mathrm{h}}$, Rick \\ Mendoza $^{f}$, Henriette Raventos $^{\mathrm{c}}$, Alfonso Ontiveros ${ }^{\mathrm{d}}$, Humberto Nicolini ${ }^{\mathrm{e}}$, Raymond Palmeri, \\ and Michael Escamilla ${ }^{a, b}$ \\ aPsychiatric Genetics Research Center, Department of Psychiatry, University of Texas Health \\ Science Center at San Antonio, San Antonio, Texas \\ bepartment of Cellular and Structural Biology, University of Texas Health Science Center at San \\ Antonio, San Antonio, Texas \\ ${ }^{\circ}$ Centro de Investigación en Biologia Celular y Molecular and Department of Genetics, School of \\ Biology, University of Costa Rica. San Jose, Costa Rica \\ dInstituto de Información e Investigación en Salud Mental, A.C \\ eGrupo de Estudios Médicos y Familiares Carraci. Mexico City \\ 'Department of Psychiatry, David Geffen School of Medicine at UCLA, Torrence, California \\ gLangley Porter Psychiatric Institute, University of California at San Francisco, San Francisco, \\ California \\ hFamily Health Centers of San Diego, San Diego, California \\ 'Department of Family Practice, University of Texas Health Science Center at San Antonio, San \\ Antonio, Texas
}

\section{Abstract}

Objective-Variation in the serotonin transporter gene (SLC6A4) promoter region has been shown to influence depression in persons who have been exposed to a number of stressful life events.

\begin{abstract}
Method-We evaluated whether genetic variation in 5-HTTLPR, influences current depression, lifetime history of depression and quantitative measures of depression in persons with chronic psychotic disorders. This is an association study of a genetic variant with quantitative and categorical definitions of depression conducted in the Southwest United States, Mexico, and Costa Rica. We analyzed 260 subjects with a history of psychosis, from a sample of 129 families.
\end{abstract}

Results-We found that persons carrying at least one short allele had a statistically significant increased lifetime risk for depressive syndromes ( $\mathrm{p}<.02$, Odds Ratio=2.18, 95\% CI=1.10-4.20).

Corresponding Author: Dr. Michael A. Escamilla, Department of Psychiatry, University of Texas Health Science Center at San Antonio, 7703 Floyd Curl Drive, San Antonio, TX 78229, Tel (210) 562 5108, Fax (210) 562 5114, escamillam@uthscsa.edu.

Declaration of Interest

This study does not involve pharmaceutical companies or other private enterprises. 
Conclusion-The "ss" or "sl" genotype at the 5-HTTLPR promoter polymorphic locus increases the risk of psychotic individuals to develop major depression during the course of their illness.

\section{Keywords}

Serotonin transporter polymorphism; depression; psychosis

\section{Introduction}

The serotonin transporter protein plays a crucial role in regulating the intensity and duration of serotonergic signaling at synapses (1) and has been a target for many psychiatric drugs (2-4). This protein is encoded by a single gene (SLC6A4, Locus Link ID: 6532), which has been mapped to chromosome 17q11.1-q12 (5). There are at least two polymorphic variants that play a role in differential expression of the SLC6A4 gene. Several studies have analyzed the role of these variants in anxiety and depression (6-11). Two of these studies (Caspi et al., 10 and Kendler et al. 11) studied the association of an insertion/deletion (s/l) variant in the promoter region of this gene with depression in the context of stressful life events. In both of these studies, variation in the promoter region of the serotonin transporter gene was shown to influence depression in persons who have been exposed to a number of stressful life events. Alleles with the deletion are coded as "s" for short form of the allele, and those with the insertion are coded "l" for long form. Individuals can be genotyped as ss, sl, or 11 (carrying two copies of the deletion, one copy of the deletion, or no copies of the deletion, respectively).

Caspi et al., 2003 (10) found that current depressive symptoms, diagnosable depression and suicidality in individuals were associated with having one or two copies of the "s" allele, but only in the context of stressful life events. Kendler et al., 20065 (11) were able to partially replicate this finding, showing in an independent sample that individuals with two $s$ alleles showed an increased risk of depression in the last year, in the context of stressful life events. Many other researchers have recently contributed to this area of research (12-15). The s allele has been reported to effect the expression of the SLC6A4 gene, resulting in decreased expression of the serotonin transporter (5-HTT) protein (16). Hranilovic et al., 2004 (17) studied differences in expression between persons with ss, sl, or 11 genotypes and found that the s allele acted in a dominant fashion; having one or two copies of the $\mathrm{s}$ allele resulted in reduced expression of 5-HTT of $27 \%$ and $30 \%$ respectively, compared to expression in individuals with the 11 genotype. Due to the effects of this genetic variation on expression, and the known role of serotonin in a variety of disorders, variation in the SLC6A4 gene has been suggested as potentially underlying a number of psychiatric disorders (18-24).

A potential role of the serotonin transporter protein in schizophrenia was suggested by a study showing that there was decreased paroxetine binding to the 5-HTT protein in the hippocampus of subjects with schizophrenia (25). Yet, direct association of the 5-HTTLPR $\mathrm{S} / \mathrm{L}$ genotype and the categorical phenotype of schizophrenia have been for the most part negative (26), (27), (28). One potential consequence of carrying the $S$ polymorphic variant might be that it might act as a modifier for the course of illness in persons who have a primary psychotic disorder by leading to increased depressive features during the person's lifetime. Depressive features, including depressive syndromes and symptoms commonly associated with depression, such as suicidality, are common in schizophrenics, with some studies suggesting that at least $25 \%$ of schizophrenic subjects may experience comorbid depression (29). The 1996 study of Dean and colleagues found that decreased paroxetine binding to the 5-HTT protein was most apparent in individuals who had committed suicide (30). To our knowledge, there has been only one study that has tested the hypothesis that the $\mathrm{S}$ variant of the 5-HTTLPR might play a direct role in increasing risk of depression in 
persons who suffer from psychotic disorders. Golimbet and colleagues found that patients with the SS genotype scored significantly higher on Guilt Feelings and Depression Items as compared with those of the LL genotype (31).

Different studies (32) suggest that the presence or absence of the s allele in the promoter region of the SLC6A4 gene is a key mediator of the brain's adaptative response to stress (33) and the study of Golimbet et al (31) suggests that it plays a potentially similar role in persons with schizophrenia. Schizophrenic subjects (or subjects with chronic psychosis) experience a higher number of adverse life events, in comparison to the general population, with increased histories of unemployment, homelessness, difficulties with marital relationships, and medical and legal problems (34). We studied subjects recruited from a genetic study of schizophrenia who had a clinical (hospital) diagnosis of schizophrenia. We argue that having a chronic psychotic disorder could function as a major adverse life event, and that in this context, variation of the 5-HTTPR would predict risk of lifetime and current depression. We hypothesized that in these subjects, those with at least one copy of the 5HTTPR "s" allele would have a greater history of lifetime and current depression than those subjects who had an "1/l" genotype. We also tested for interaction between lifetime psychosis culled from a recently developed instrument called the Lifetime Dimensions of Psychosis Scale (35) and depression, based on "s" and "l" genotype. Although some recent studies have suggested that finer genotyping of the "l" allele can yield additional information, our budget did not allow us to explore the "tri-allelic" hypothesis. We therefore limit this study to the effects of the "s" and "l" variants on depression in the context of psychosis.

\section{Aims of the study}

Our aims were to examine this association using three theoretically correlated definitions of depression: i) a history of lifetime depressive syndrome or episode based on categorical diagnosis, ii) a current depressive syndrome or episode at the time of interview ("last 30 days") and iii) a dimensional measure of lifetime depression.

\section{Material and methods}

\section{Subjects}

Ascertainment: Subjects were originally recruited for a family based linkage study of schizophrenia and schizoaffective disorder conducted in Mexico, the Southwest United States, Guatemala and Costa Rica (36). Families were eligible for study if they had at least two siblings with hospital or clinic diagnoses of schizophrenia or schizoaffective disorder. In each family, all subjects with a history of psychotic disorder, as determined through family review using the

Family Interview for Genetic Studies (FIGS), underwent the full diagnostic and best estimate consensus process. Two hundred and sixty subjects (from 129 families) had a lifetime history of psychosis. The mode of subjects per family was 2 (minimum 1, maximum 6). Sixty-one percent of these subjects were male. The mean age at time of interview was 37.9 (standard deviation $=11.68$ ). Out of the 260 individuals 155 had lifetime history of depressive syndrome. The genotype distribution was "ss" 95 (36\%), "sl" $116(45 \%)$ and "ll" 49 (19\%). Forty-seven percent of the subjects were recruited in Mexico, 39\% were from the Southwest United States, and 16\% were from Central America. All subjects were of Latino ancestry.

In a set of secondary analyses, using different methodology to ensure independence of subjects analyzed in this current paper, only one subject per family (the first subject with a 
hospital diagnosis of schizophrenia or schizoaffective disorder recruited in each family) was used for the statistical analyses presented below. One hundred and twenty-nine subjects were included in these analyses: 60 (47\%) were recruited from sites in Mexico (32 from Monterrey, 28 from Mexico City), 48 (39\%) were recruited from sites in the Southwest United States (26 from San Antonio, 14 from Los Angeles, 8 from San Diego), and 21 (16\%) from Costa Rica. This secondary sample consisted of fifty-three females and seventysix males with a mean age at participation of 37.45 years (standard deviation +/- 10.37). Demographic information for this set of individuals is presented in Table 1.

Diagnostic Process: Each subject was interviewed in their native language, by a psychiatrist fluent in that language, using the DIGS (Diagnostic Interview for Genetic Studies) (37). A consensus best estimate review process, utilizing direct interview with the patient (DIGS interview), FIGS interview with a close relative of the patient, and review of any available medical or psychiatric records, was utilized to arrive at final categorical diagnoses, using DSM IV criteria. Details of the instrument development, standardization, training and reliability of the diagnostic process can be found elsewhere (37). Although each subject study had an outpatient or inpatient diagnosis of schizophrenia or schizoaffective, hospitals in the United States, Mexico, and Costa Rica often use different clinical diagnostic systems which are not always compatible, and previous studies in the Latino population have shown that a more rigorous, standardized diagnostic process often reveals a spectrum of closely related psychotic disorders can receive hospital diagnoses of schizophrenia or schizoaffective disorder (38). All subjects had, according to best estimate consensus, a history of psychosis, as defined by Criteria A for DSM-IV Schizophrenia. Specific consensus DSM-IV diagnoses of the full sample of psychotic subjects were as follows: Schizophrenia (201), Schizoaffective Disorder Bipolar Type (27), Schizoaffective Depressed Type (9), Bipolar Disorder (9), Psychotic Disorder Not Otherwise Specified (9), Major Depressive Disorder with Psychosis (4), and Psychosis secondary to a Medical Condition (1). In the smaller sample of one person per family, the breakdown of diagnoses was as follows: Schizophrenia (105), Schizoaffective Disorder (18), Psychosis Not Otherwise Specified (2), Bipolar Disorder (2), Major Depressive Disorder with psychosis (2).

\section{Measures of Depression}

Categorical measures: During the best estimate diagnostic procedure, diagnosticians arrived at consensus for whether or not each subject had ever had a full major depressive syndrome (as defined by criteria A for Major Depressive Episode in the DSM-IV). Lifetime history and current history of having a full major depressive syndrome or episode were the two categorical variables our primary categorical variable tested in the current study. For defining current syndrome or episode, presence or absence was determined by reviewing the current symptoms of depression and their duration, as captured in the DIGS.

Dimensional measures: The Lifetime Dimensions of Psychosis Scale (LDPS) includes measures of depression, and is designed for use in studying subjects with psychotic disorders (35). The LDPS is designed for experienced clinicians who have access to comprehensive clinical information, including semi-structured diagnostic interviews, psychiatric records, and family history reports. To generate a dimensional index of lifetime depression severity, we multiplied the severity score (from 0 to 4 ) with the lifetime duration score (from 0 to 4 ) to arrive at a variable for depression that could range from 0 to 16 . The distribution for this index for the complete sample are shown in Figure 1. Secondary dimensional analyses for depressive features included duration of depression, severity of depression, and the number of symptoms of depression. For psychosis, we utilized the P-1 
(any delusions) and P-3 (any hallucinations) dimensions from the LDPS, with variables ranging from 0 to 16 for each of these dimensions.

\section{Genotyping}

Peripheral blood was collected to create lymphoblastic cell lines. Genomic DNA was extracted from transformed lymphocytes by a standard procedure as described in Lahiri and Nurnberger (39). PCR for the 5-HTTLPR polymorphism was performed in a total volume of $15 \mu \mathrm{l}$ containing $1.8 \mathrm{mM} \mathrm{MgCl} 2,200 \mathrm{mM}$ of each dATP, dCTP and dTTP, $100 \mathrm{mM}$ each of dGTP, and 7-deaza-dGTP, 0.96 units of AmpliTaq Gold polymerase (AmpliTaq Gold; Perkin Elmer, Norwalk, CT, USA), $1.3 \mu \mathrm{M}$ primers (5'GGC GTT GCC GCT CTG AAT TGC and 5' GAG GGA CTG AGC TGG ACA ACC CAC) (40) and $150 \mathrm{ng}$ of genomic DNA. After an initial 10-minutes denaturation step at $95^{\circ} \mathrm{C}, 45$ cycles were performed consisting of $30 \mathrm{~s}$ at $95^{\circ} \mathrm{C}, 30 \mathrm{~s}$ at $61^{\circ} \mathrm{C}$ and $1 \mathrm{~min}$ at $72^{\circ} \mathrm{C}$, followed by a final step of $7 \mathrm{~min}$ at $72^{\circ} \mathrm{C}$. PCR products were separated on $2 \%$ high-melt agarose gel and visualized by UV after ethidium bromide staining. Genotyping was performed in Mexico City and scoring of alleles was performed by technicians bind to diagnostic status and clinical history of the subjects.

\section{Statistical analysis}

Campos-Sánchez et al (41) independently analyzed the genetic relationships of subjects collected in Costa Rica, Mexico City, and the Southwest United States, and found that they constitute a group with similar ancestral DNA characteristics and can be reasonably analyzed as a homogeneous group for purposes of combined analysis. Subjects were divided into two groups based on presence or absence of an " $S$ " genotype: 49 subjects were in Group 1 (LL genotype), and the remaining 211 were classified as Group 2 (116 who had an SL genotype and 95 who had an SS genotype). Groups were clustered in this manner, since the $\mathrm{S}$ genotype is known to function in a dominant manner with regard to suppression of transcription of the 5-HTT gene (7). To test for possible stratification between these two groups, we also analyzed genotype frequencies for 20 markers genotyped in these same subjects. The 20 markers were chosen at random from a set of markers previously genotyped by the Center for Inherited Disease Research (36), spanning the genome and included the following microsatellites: D1S1588, D1S1663, D1S2141, D3S4523, D3S2427, D4S1644, D5S2849, D5S820, D5S211, D7S3046, D7S2204, D7S3058, D10S1225, D10S1432, D11S2002, D14S587, D15S1507, D17S1301, D18S843, D22S445. Genotypes appearing less than five times were collapsed into one genotype class. Chi-square analyses were performed to evaluate whether there were statistically significant differences $(p<.05)$ for the genotype frequencies for the "ss/sl" group and the "ll" group of subjects at any of these markers.

LDPS score of items DE-1 was tested for normal distribution in the sample of 129 (one psychotic subject per family). Duration x severity of symptoms was not normally distributed in the whole sample. However it was normally distributed ( $>>0.05)$ in the group of individuals with life-time history of depression (Shapiro-Wilk and Kolmogorov-Smirnov Test with Lilliefors significance correction).

For the full sample (all 260 subjects with a history of psychosis), we analyzed whether a lifetime history of depressive syndrome or episode was associated with the 5-HTTLPR S/L genotype. For these analyses, descriptive statistics were calculated using SAS software (42). Because individual subject data were nested within families, hierarchical regression methods were used to correct for potential type-1 error due to grouped family data. A multilevel logistic regression model was carried out using MIWin (43) Software. A genotype variable was created where subjects possessing an SS or SL genotype were coded as 1, and those 
with LL were coded as 0 . This dummy variable was used as a predictor of a dichotomous depression variable. A 2nd model was run adjusting for gender and age.

This same analysis (lifetime history of depressive episode or syndrome) as well as several additional analyses (current depressive episode/syndrome, severity and duration of LDPS depression scores) were performed on the subset of one subject per family ( $\mathrm{n}=129$ subjects with a history of psychosis). Age of subjects can have an effect on the LDPS duration score and gender is a known factor in differential risk of lifetime depression (44). Therefore we compared the two genotype groups (Group 1 and 2) with regard to these two variables. The percentage of females in Group 1 (LL genotype) was slightly higher, and the age of Group 2 (SL or SS genotype) was slightly higher, however these differences were not statistically significant between groups for either of these two variables (age $(\mathrm{p}=0.197)$ and gender $(\mathrm{p}=0.516)$, Table 1). Chi square scores were calculated to evaluate association between the genotype and lifetime history of depressive syndrome and current depressive syndrome (categorical diagnoses). To test for association of genotype groups and dimensional measures of depression, we utilized the ANOVA least square means statistical test, covering for age and gender. In all of the tests, the criterion for significance was set atp $<0.05$.

Corrections for multiple testing were not utilized, as the measures of depression we were testing are most likely very highly correlated and are not independent factors. Analyses were conducted with SPSS 15 software. We also tested the hypothesis that genotype (ss or sl, versus 11) would interact with the dimension of lifetime psychosis, to cause increased depressive symptoms. Using the dimensions of lifetime delusions and lifetime hallucinations (P-1 and P-3 from the LDPS), we tested for possible correlation between each of these psychotic symptoms and the LDPS dimension of lifetime depression. Correlations were tested independently for the ss/sl group and the 11 genotype group.

\section{Results}

For the full sample of 260 subjects with psychosis, the null model (no predictors) indicates that there was no significant level 2 variation in the outcome variable (lifetime depression) (level 2 variance $=.26$, standard error $=.29, \mathrm{p} 0.92$ ). This indicates that variation in lifetime depression was not influenced by familiar clustering in this sample. Sixty percent of the subjects had had a lifetime history of at least one full depressive episode or syndrome. The 5-HTTLPR marker used for this analysis was in Hardy-Weinberg equilibrium. The regression coefficient for the genotype variable was statistically significant $(b=.73(.34), p$ $<.02 ; \mathrm{OR}=2.07,95 \% \mathrm{CI}=1.14-3.95$ ) indicating that those possessing either the SS or SL genotype were 2.07 times more likely to be categorized as having had a full syndrome/ episode of depression during their lifetime. In the adjusted model, the regression coefficient for the genotype variable not only remains significant but increases slightly $(b=.78(.36), p$ $<.02 ; \mathrm{OR}=2.18,95 \% \mathrm{CI}=1.10-4.20$ ). For the sample of 129 individuals with history of psychosis (one per family), the majority suffered a full episode or syndrome of major depression during their lifetime (77 individuals, $60 \%$ of the total sample). We found a significant association between the SS or SL genotype (genotype group 2) and lifetime history of depression $\left(x^{2}=4.211, \mathrm{df}=1, \mathrm{p}=0.040\right.$, Table 1 . In those 77 individuals who developed a depressive syndrome at some point in their life, almost all subjects developed depressive syndromes in the same year or at later age than the onset of psychosis (68, $(92 \%))$. As our hypothesis was that psychosis is the primary stressor, we also analyzed the subjects, limited to only those subjects where depression occurred during the same year or after the onset of psychosis; the results still showed that having an SS or SL genotype (Group 2) was significantly associated to having had a history of a major depressive syndrome $(\mathrm{p}=0.029)$. We also analyzed this association for the subset of schizophrenic individuals. These results still showed that having an SS or SL genotype was significantly associated to history of a major depressive syndrome. We replicated this analysis in a 
subsample were the second recruited subject of each family was assessed (103 individuals). Fifty three subjects had history of depressive syndrome, 83 had "ss/sl" genotype and 20 "ll" genotype. The association of "ss/sl" genotype with depression remained significant $\left(\mathrm{x}^{2}=4.5\right.$, $\mathrm{p}=.32$ ).

In terms of current depression, 19 of the 129 individuals met criteria for a full syndrome of depression (14.7\% of the total sample). Interestingly, none of the individuals with an LL genotype had a current depressive syndrome. Having an SS or SL genotype was significantly associated with presence of a current major depressive syndrome $\left(\mathrm{X}^{2}=6.39\right.$, $\mathrm{p}=0.012$, Table 1).

Individuals with genotype SS or SL genotype had significantly elevated scores for the LDPS dimension of depression (LDPS DE 1 duration $\mathrm{x}$ severity, $\mathrm{p}=.046$ ), as well as the dimensional scores for lifetime duration of depressive features (LDPS DE1 duration, $\mathrm{p}=$. 050), lifetime severity of depressive symptoms (LDPS DE-1 severity, $\mathrm{p}=.050$ ), and maximum number of depressive symptoms during their lifetime (LDPS DE-2 score, $\mathrm{p}=$. 019). The LDPS scale was not useful as a dimensional variable for subjects who had never had a history of a full depressive syndrome, as variance in those subjects was limited to either a 0 or a 1 (LDPS DE1 duration X severity). Within subjects that had a positive history of depressive syndromes, this dimension showed a normal distribution curve, as shown in Figure 1.

As a secondary analysis, Figures 2 and 3 show the breakdown of the categorical and dimensional measures, with relation to the three distinct genotype groups (LL, SL, and SS). As expected, persons with one or two copies of the $\mathrm{S}$ allele showed similar rates of depression (both categorically and dimensionally, which is consistent with previous literature suggesting the " $\mathrm{s}$ " allele acts in a dominant manner with regard to effecting RNA expression of the transporter gene. On all 6 measures, persons with an SS versus and SL genotype showed no statistical difference in terms of lifetime or current depression $(0.40<\mathrm{p}<$ $0.91)$.

In terms of lifetime dimensional measures of psychosis and depression, we found positive correlation between delusions and depression $(\mathrm{p}=.028)$ and hallucinations and depression $(\mathrm{p}=.029)$ in the SS/SL group (Figure 4). In the LL group there was no correlation between either delusions and depression or hallucinations and depression.

Tests for possible stratification in the 20 random microsatellite markers yielded only 2 markers which showed genotype frequency differences at a level of $p<.05$ between the two groups of subjects (Group 1 being individuals with an ss or sl genotype, and Group 2 being individuals with an 11 genotype). This is slightly more than would be predicted by chance $(1 / 20)$ if there were no stratification between these two groups.

\section{Discussion}

Patients with hospital diagnoses of schizophrenia and schizoaffective disorder are at great risk for lifetime history of a full depressive syndrome or episode. In the full sample, sixty percent of the subjects with a history of psychosis also had a history of depressive episodes or syndromes, which is consistent with studies that have investigated the extent of depression in subjects with chronic psychotic disorders (45). Within the group of 129 subjects (one per family) with a strict, post best estimate consensus diagnosis of Schizophrenia, $45 \%$ had a lifetime history of major depressive syndromes, consistent with previous studies (46). This high rate of depression may be a factor in the high rates of suicide attempts and suicidal completion in people who suffer from schizophrenia, which may run as high as $20 \%-40 \%$ and $5-13 \%$ respectively (47). 
In terms of current depression, the rates are still above most epidemiologic reports culled from the general population (48). Of special note, in our sample all of the subjects with a current depressive syndrome were subjects who had either one or two copies of the " $\mathrm{S}$ " allele of 5HTT-PR polymorphism.

Our results are consistent with the dominant model suggested by Hranilovic et al. (17) and showed in both the full sample analysis and the smaller (one per family analysis) that having an "ss" or "sl" genotype increased risk of lifetime depression. Interestingly, we also show that the lifetime dimension (duration $\mathrm{x}$ severity) of delusions and hallucinations both correlate with increased lifetime depression, but only in persons with an "ss" or "sl" genotype. Those with an "ll" genotype did not show this correlation between psychosis and depression which was also replicated in the subsample of second recruited subject for each family. We therefore conclude that in our sample, the "s" variant confers increased risk for depression in the context of psychotic illness.

Interestingly, we found, when looking at dimensional ratings, that carriers of an S allele showed longer duration of depression during their lifetime, greater severity of depression when it did occur, and a greater number of depressive symptoms during the worst episode. Although these aspects of depression might all be strongly correlated (for instance it is known that lifetime prevalence of depressive episodes correlates strongly with presence or absence of a current depressive episode), we find it interesting that the effects of having an $S$ allele appear to affect severity as well as duration of depressive symptoms within persons who have a chronic disorder. These findings are consistent, in a new sample and new type of population, with the findings of Golimbet et al (31), who also showed, in patients with chronic psychosis, that increased rates of several depressive symptoms was associated with having an SS or SL genotype. Moreover, we have shown that not only symptoms but full depressive syndromes are associated with patients with chronic psychosis who have an SS or SL genotype and that this association exists for both current and past episodes of depression.

An increased number of adverse life events were a necessary condition in order to see a role of this polymorphism in predicting depression in both the Caspi et al (10) and Kendler et al (11) studies, which studied people from general population samples. We hypothesized that chronic psychosis might itself act as a "stressor" which might interact with the s/l serotonin transporter variant to increase depression in persons with at least one copy of the "s" variant. Since we did not have information on life stressors, we could not test the hypothesis that specific life stressors interact with this genotype to increase depression. It is possible that there might be a correlation between life stressors and the duration of severity of psychotic symptoms, however this is not directly addressable with our data.

One can hypothesize several potential pathways which might explain the high rates of depression in persons with a psychotic disorder. Lack of personal security, living conditions potentially harmful to the patients' psychological well-being, persecution and discrimination, bad peer relationships and unemployment are all potential sequelae of problems of interaction between the psychotic individual and his/her environment. For persons whose psychosis carries a paranoid element, as argued by Birchwood et al, the presumed threat from persecutors to the individual's well being may be sufficient to trigger depression and fear (49). For those patients who have sufficient insight to be aware of their illness and how it impacts their life, awareness of illness may be a direct trigger for a potentially dysphoric response. Post-psychotic depression, for instance, is a common occurrence in persons who are treated for first-break psychosis (50).

In understanding why some persons are more at risk than others, we conclude that the 5HTTPR polymorphism explains some of this variance. Whether one conceives of the LL 
genotype as protective against development of full depressive episodes, or views the SS or SL genotype as a risk factor, our current results support a role for this variant in the course of illness (i.e. likelihood of developing secondary depression) of those with psychotic disorders.

Our study drew from a sample that was specially selected because the subjects had familial psychotic disorder. A limitation is that, although the major risk factor for schizophrenia is a family history, most schizophrenic subjects do not have a known family member with schizophrenia or chronic psychosis. Our study cannot be generalized to all subjects with schizophrenia, but it can be generalized to persons with familial forms of chronic psychotic conditions. In this sense, our study complements the findings of Golimbet et al (31), who drew from a more general sample of schizophrenic subjects. Another limitation of the study is that our analyses were based on comparison between two groups (ss/sl group and 11 group) and there might be underlying stratification between these groups. In finding that only 2 of 20 randomly chosen microsatellites showed statistical differences in gene frequencies between the two groups, we can say that stratification in this sample is minimal.

Nevertheless, our results should be interpreted with caution unless replicated in similar or larger samples. Family based association tests are one way to overcome the effects of potential stratification, but there were not enough informative families in our sample to test this. Another limitation of the current study is that we were not able to do additional genotyping beyond the $\mathrm{s} / \mathrm{l}$ variant. Zalsman et al 53 have recently shown that a third polymorphism in he 5HTT gene interacts with the S/L 5HTTPR variant, and this may lead to finer delineation of relative expression of the 5HTT gene. Although this is an interesting development in the study of the 5HTT gene, our limited funding limited us to studying hypotheses generated from the studies of Caspi et al (10), Kendler et al (11), and Golimbet et al. (31), which based their analyses on the S/L variation. In future studies, evaluation of all polymorphisms in the 5HTT gene will be useful in order to even more carefully evaluate how genetic variation in this gene affects the onset and course of depression in persons both with and without psychotic disorders.

How to classify the genotype groups is a question that has been addressed differently in the literature. Based on studies suggesting the "S" allele acts in a dominant fashion, we chose to do our primary analysis by clustering the SS and SL genoypes together, for a combined SS/ SL group, which is the group Caspi et al (10) found to be associated with increased risk of depressive symptoms. All of our analyses that grouped the SS and SL alleles showed significant differences, as those found by Caspi et al (10). Our secondary analyses did not show significant differences between SS and SL genotypes with regard to depressive symptoms. In the Golimbet study (31), as in the Kendler study (11), the significant comparison was between persons with an SS genotype and persons with an LL genotype. We did find significant differences between those with an SS and those with an LL genotype for current depressive syndrome $\left(\mathrm{x}^{2}=4.38, \mathrm{p}=0.037\right)$, in the expected direction (SS genotypes increasing the risk of current depression). Although we did not find significant differences between the SS and LL genotyped subjects for the other dimensions of depression, this may have been due to the smaller sample size used when the SL subjects are removed from the analysis.

An advantage of the current study is that we know these subjects have, in all likelihood, a genetic form of psychosis. It has long been shown that, in families of persons with schizophrenics, one often sees relatives with schizoaffective disorder (51); why one person develops schizophrenia and another develops schizoaffective disorder has been an open question, although some have hypothesized that this may be in part due to modifying genes (52). Given that, it is interesting to consider that our study provides evidence that the 5HTTPR polymorphism may actually act as a modifier in genetic forms of psychosis. For 
instance, according to the DSMIV, the difference between schizoaffective depressed disorder and schizophrenia, when a subject has had depression in the context of a chronic psychosis, is the relative duration of the depressive syndromes to the psychotic symptoms. Indeed, in the current study, persons with the LL variant ended up with a consensus diagnosis of schizophrenia (rather than schizoaffective disorder) more often than did those who had an SS or SL variant. Given that our study shows that this polymorphism is associated with increased severity and duration of depressive symptoms, it should be considered a possible modifier for genetic forms of psychosis.

Although, with only this and the study of Golimbet et al (31) showing the association of the $S$ variant and increased symptoms of depression in persons with chronic psychosis, one must be cautious about generalizations, these results do offer some potential lines for further research. Genotyping of the 5HTTPR may be a potential clinical tool when treating persons with new onset psychosis or chronic psychosis. For instance, having one or more copy of the $\mathrm{S}$ allele might suggest that treatment strategies might include antidepressants or atypical antipsychotic medications which can help compensate for the decreased expression of the 5HTT gene and, secondarily, the increased risk of developing secondary depression. Carefully controlled, prospective medication trials will be necessary to test this. Of special interest will be prospective studies in persons with chronic psychosis who have not yet developed depression. Given the high rates of suicidality and suicide attempts in persons with schizophrenia (46-48) and the likely high consequences of comorbid depression on top of a chronic psychotic disorder, additional studies of how to decrease depressive comorbidity in persons with schizophrenia may help us to substantially improve our treatment paradigms for persons who suffer from and are trying to overcome the consequences of psychotic conditions.

\section{Acknowledgments}

This work was supported by Grants \#R01 MH60881 and R01 60875 from the National Institute of Mental Health and the US/CR Psychiatric Genetic Research Training Grant \#D43 TW006152-04 (PGID \#115887). We are grateful to the families who participated in this research study and to the support of the Fogarty Foundation and the National Institute of Mental Health for funding support. We acknowledge the contributions of Dr. Patricia Montero, Dr. Rodolfo Salazar and the investigative teams at each site. We also thank the families that participated in this study.

\section{References}

1. Mantere T, Tupala E, Hall H, et al. Serotonin transporter distribution and density in the cerebral cortex of alcoholic and nonalcoholic comparison subjects: a whole-hemisphere autoradiography study. Am J Psychiatry. 2002; 159:599-606. [PubMed: 11925298]

2. Murphy GM Jr, Hollander SB, Rodrigues HE, et al. Effects of the serotonin transporter gene promoter polymorphism on mirtazapine and paroxetine efficacy and adverse events in geriatric major depression. Arch Gen Psychiatry. 2004; 61:1163-9. [PubMed: 15520364]

3. Alessandro S, Kato M. The serotonin transporter gene and effectiveness of SSRIs. Expert Rev Neurother. 2008 Jan; 8(1):111-20. [PubMed: 18088204]

4. Stamm TJ, Adli M, Kirchheiner J, Smolka MN, Kaiser R, Tremblay PB, Bauer M. Serotonin transporter gene and response to lithium augmentation in depression. Psychiatr Genet. 2008 Apr; 18(2):92-7. [PubMed: 18349701]

5. Rammoorthy S, Bauman AL, Moore KR, Han H, Yang-Feng T, Chang AS. Antidepressant-and cocaine sensitive human serotonin transporter: molecular cloning, expression, and chromosomal localization. Proc Natl Acad Sci USA. 1993; 90:2542-2546. [PubMed: 7681602]

6. Stein MB, Schork NJ, Gelernter J. Gene-by-environment (serotonin transporter and childhood maltreatment) interaction for anxiety sensitivity, an intermediate phenotype for anxiety disorders. Neuropsychopharmacology. 2008 Jan; 33(2):312-9. [PubMed: 17460615] 
7. Kilpatrick DG, Koenen KC, Ruggiero KJ, Acierno R, Galea S, Resnick HS, Roitzsch J, Boyle J, Gelernter J. The serotonin transporter genotype and social support and moderation of posttraumatic stress disorder and depression in hurricane-exposed adults. Am J Psychiatry. 2007 Nov; 164(11): 1693-9. [PubMed: 17974934]

8. Uher R, McGuffin P. The moderation by the serotonin transporter gene of environmental adversity in the aetiology of mental illness: review and methodological analysis. Mol Psychiatry. 2008 Feb; 13(2):131-46. [PubMed: 17700575]

9. Currier D, Mann JJ. Stress, genes and the biology of suicidal behavior. Psychiatr Clin North Am. 2008 Jun; 31(2):247-69. [PubMed: 18439448]

10. Caspi A, Sugden K, Moffitt TE, et al. Influence of life stress on depression: moderation by a polymorphism in the 5-HTT gene. Science. 2003; 301:386-389. [PubMed: 12869766]

11. Kendler KS, Kuhn JW, Vittum J, Prescott CA, Riley B. The interaction of stressful life events and a serotonin transporter polymorphism in the prediction of episodes of major depression: a replication. Arch Gen Psychiatry. 2005 May; 62(5):529-35. [PubMed: 15867106]

12. Gotlib IH, Joormann J, Minor KL, Hallmayer J. HPA axis reactivity: a mechanism underlying the associations among 5-HTTLPR, stress, and depression. Biol Psychiatry. 2008 May 1; 63(9):84751. [PubMed: 18005940]

13. Brummett BH, Boyle SH, Siegler IC, Kuhn CM, Ashley-Koch A, Jonassaint CR, Züchner S, Collins A, Williams RB. Effects of environmental stress and gender on associations among symptoms of depression and the serotonin transporter gene linked polymorphic region (5HTTLPR). Behav Genet. 2008 Jan; 38(1):34-43. [PubMed: 17955359]

14. Kim JM, Stewart R, Kim SW, Yang SJ, Shin IS, Kim YH, Yoon JS. Interactions between life stressors and susceptibility genes (5-HTTLPR and BDNF) on depression in Korean elders. Biol Psychiatry. 2007 Sep 1; 62(5):423-8. [PubMed: 17482146]

15. Bah J, Lindström M, Westberg L, Mannerås L, Ryding E, Henningsson S, Melke J, Rosén I, Träskman-Bendz L, Eriksson E. Serotonin transporter gene polymorphisms: effect on serotonin transporter availability in the brain of suicide attempters. Psychiatry Res. 2008 Apr 15; 162(3): 221-9. [PubMed: 18314311]

16. Glatz K, Mossner R, Heils A, Lesch KP. Glucocorticoid-regulated human serotonin transporter (5HTT) expression is modulated by the 5-HTT genepromotor-linked polymorphic region. J Neurochem. 2003; 86:1072-8. [PubMed: 12911615]

17. Hranilovic D, Stefulj J, Schwab S. Serotonin transporter promoter and intron 2 polymorphisms: relationship between allelic variants and gene expression. Biol Psychiatry. 2004; 55:1090-4. [PubMed: 15158428]

18. Feinn R, Nellissery M, Kranzler HR. Meta-analysis of the association of a functional serotonin transporter promoter polymorphism with alcohol dependence. Am J Med Genet B Neuropsychiatr Genet. 2005; 133:79-84. [PubMed: 15635638]

19. Cho HJ, Meira-Lima I, Cordeiro Q, et al. Population-based and family-based studies on the serotonin transporter gene polymorphisms and bipolar disorder: a systematic review and metaanalysis. Mol Psychiatry. 2005; 10:771-81. [PubMed: 15824745]

20. Lasky-Su JA, Faraone SV, Glatt SJ, Tsuang MT. Meta-analysis of the association between two polymorphisms in the serotonin transporter gene and affective disorders. Am J Med Genet B Neuropsychiatr Genet. 2005; 133:110-5. [PubMed: 15578606]

21. Sen S, Burmeister M, Ghosh D. Meta-analysis of the association between a serotonin transporter promoter polymorphism (5-HTTLPR) and anxiety-related personality traits. Am J Med Genet B Neuropsychiatr Genet. 2004; 15;127:85-9.

22. Richardson J, Steiger H, Schmitz N, Joober R, Bruce KR, Israel M, Gauvin L, Anestin AS, Dandurand C, Howard H, de Guzman R. Relevance of the 5-HTTLPR Polymorphism and Childhood Abuse to Increased Psychiatric Comorbidity in Women With Bulimia-Spectrum Disorders. J Clin Psychiatry. 2008 May 20.:e1-e10. [PubMed: 18312028]

23. Retz W, Freitag CM, Retz-Junginger P, Wenzler D, Schneider M, Kissling C, Thome J, Rösler M. A functional serotonin transporter promoter gene polymorphism increases ADHD symptoms in delinquents: interaction with adverse childhood environment. Psychiatry Res. 2008 Mar 15; 158(2):123-31. Epub 2007 Dec 26. [PubMed: 18155777] 
24. Ramasubbu R, Tobias R, Bech-Hansen NT. Extended evaluation of serotonin transporter gene functional polymorphisms in subjects with post-stroke depression. Can J Psychiatry. 2008 Mar; 53(3):197-201. [PubMed: 18441666]

25. Dean B, Opeskin K, Pavey G, et al. [3H] paroxetine binding is altered in the hippocampus but not the frontal cortex or caudate nucleus from subjects with schizophrenia. J Neurochem. 1995; 64:1197-202. [PubMed: 7861151]

26. Stober G, Jatzke S, Heils A, et al. Susceptibility for schizophrenia is not influenced by a functional insertion/deletion variant in the promoter of the serotonin transporter gene. Eur Arch Psychiatry Clin Neurosci. 1998; 248:82-86. [PubMed: 9684917]

27. Serretti A, Lilli R, Lorenzi C, Lattuada E, Cusin C, Smeraldi E. Serotonin transporter gene (5HTTLPR) and major psychoses. Mol Psychiatry. 2002; 7:95-99. [PubMed: 11803453]

28. Mendes de Oliveira JR, Otto PA, Vallada H, et al. Analysis of a novel functional polymorphism within the promoter region of the serotonin transporter gen (5-HTT) in Brazilian patients affected by bipolar disorder and schizophrenia. American Journal of Medical Genetics (Neuropsychiatric Genetics). 1998; 81:225-227. [PubMed: 9603609]

29. Ross RG, Heinlein S, Tregellas H. High rates of comorbidity are found in childhood-onset schizophrenia. Schizophr Res. 2006; 88:90-5. [PubMed: 16916600]

30. Dean B, Hayes W, Opeskin K, Naylor L, Pavey G, Hill C, Keks N, Copolov DL. Serotonin2 receptors and the serotonin transporter in the schizophrenic brain. Behav Brain Res. 1996; 73:16975. [PubMed: 8788497]

31. Golimbet VE, Alfimova MV, Shchebatykh TV, Abramova LI, Kaleda VG, Rogaev EI. Serotonin transporter polymorphism and depressive-related symptoms in schizophrenia. Am J Med Genet B Neuropsychiatr Genet. 2004; 126:1-7. [PubMed: 15048639]

32. Kaufman, Joan; Yang†, Bao-Zhu; Douglas-Palumberi, Heather, et al. Social supports and serotonin transporter gene moderate depression in maltreated children. Proc Natl Acad Sci USA. 2004; 49:17316-17321. [PubMed: 15563601]

33. Lecomte Y, Mercier C. The stress process perspective and adaptation of people with schizophrenia--an exploratory study. Soc Psychiatry Psychiatr Epidemiol. 2005; 40:139-48. [PubMed: 15685406]

34. Horan WP, Ventura J, Nuechterlein KH, Subotnik KL, Hwang SS, Mintz J. Stressful life events in recent-onset schizophrenia: reduced frequencies and altered subjective appraisals. Schizophr Res. 2005 Jun 15; 75(2-3):363-74. [PubMed: 15885527]

35. Levinson DF, Mowry BJ, Escamilla MA, Faraone SV. The Lifetime Dimensions of Psychosis Scale (LDPS): description and interrater reliability. Schizophr Bull. 2002; 28:683-95. [PubMed: 12795498]

36. Escamilla MA, Ontiveros A, Nicolini H, et al. A genome-wide scan for schizophrenia and psychosis susceptibility loci in families of Mexican and Central American ancestry. Am J Med Genet B Neuropsychiatr Genet. 2007; 144:193-9. [PubMed: 17044102]

37. Nurnberger JI Jr, Blehar MC, Kaufman CA, et al. Diagnostic interview for genetic studies. Rationale, unique features, and training. NIMH Genetics Initiative. Arch Gen Psychiatry. 1994; 51:849-859. [PubMed: 7944874]

38. Montero AP, Balderas T, Pereira M, et al. Resultados de la categorizacion de una muestra de pacientes con diagnostico de Esquizofrenia. Acta Medica Costarricense. 2002; 44(2):74-78.

39. Lahiri DK, Nurnberger JI Jr. A rapid non-enzymatic method for the preparation of HMW DNA from blood for RFLP studies. Nucleic Acids Res. 1991; 19:5444. [PubMed: 1681511]

40. Heils A, Teufel A, Petri S, et al. Allelic variation of human serotonin transporter gene expression. J Neurochem. 1996; 66:2621-4. [PubMed: 8632190]

41. Campos-Sánchez R, Barrantes R, Silva S, et al. Genetic structure analysis of three Hispanic populations from Costa Rica, Mexico and the Southwest United States, using Y-STRs markers and mtDNA sequence. Human Biology. 2006; 78:551-563. [PubMed: 17506286]

42. SAS/STAT(R), S. I. I. Users Guide. Cary, NC: SAS Institute; 1999. Version 8 ed

43. Rasbash, J.; Steele, F.; Browne, W.; Prosser, B. A user's guide to MLwiN, Version 2.1. London: Multilevel Models Project, Institute of Education, University of London; 2004. 
44. Breslau N, Schultz L, Peterson E. Sex differences in depression: a role for preexisting anxiety. Psychiatry Res. 1995; 58:1-12. [PubMed: 8539307]

45. Birchwood M, Iqbal Z, Chadwick P, Trower P. Cognitive approach to depression and suicidal thinking in psychosis: I. Ontogeny of post-psychotic depression. Br J Psychiatry. 2000; 177:516528. [PubMed: 11102326]

46. Radomsky ED, Haas GL, Mann JJ, Sweeney JA. Suicidal behavior in patients with schizophrenia and other psychotic disorders. Am J Psychiatry. 1999; 156:1590-1595. [PubMed: 10518171]

47. Pompili M, Amador XF, Girardi P, et al. Suicide risk in schizophrenia: learning from the past to change the future. Ann Gen Psychiatry. 2007; 6:10. [PubMed: 17367524]

48. Blazer DG, Kessler RC, McGonagle KA, Swartz MS. The prevalence and distribution of major depression in a national community sample: the National Comorbidity Survey. Am J Psychiatry. 1994; 151:979-86. [PubMed: 8010383]

49. Birchwood M, Iqbal Z, Chadwick P, Upthegrove R. Psychological pathways to depression in schizophrenia. Eur Arch Psychiatry Clin Neurosci. 2005; 255:202-212. [PubMed: 15995904]

50. Oosthuizen P, Emsley R, Niehaus D, Koen L, Chiliza B. The relationships between depression and remission in first-episode psychosis. World Psychiatry. 2006; 5:172-6. [PubMed: 17139353]

51. Kendler KS, McGuire M, Gruenberg AM, O’Hare A, Spellman M, Walsh D. The Roscommon Family Study I. Methods, diagnosis of probands, and risk of schizophrenia in relatives. Arch Gen Psychiatry. 1993; 50:527-540. [PubMed: 8317947]

52. Van Erp TG, Saleh PA, Rosso IM, et al. Contributions of genetic risk and fetal hypoxia to hippocampal volume in patients with schizophrenia or schizoaffective disorder, their unaffected siblings, and healthy unrelated volunteers. Am J Psychiatry. 2002; 159:151. [PubMed: 11772714]

52. Zalsman G, Huang YY, Oquendo MA, et al. Association of a triallelic serotonin transporter gene promoter region (5-HTTLPR) polymorphism with stressful life events and severity of depresión. Am J Psychiatry. 2006; 163:1588-93. [PubMed: 16946185] 


\section{Significant Outcomes}

- The 5-HTTLPR "s" variant increases risk for depression in psychotic illness.

- This polymorphism is associated with increased severity and duration of depressive symptoms.

\section{Limitations}

- These analyses were based on comparison between two groups (ss/sl and 1l) and there might be underlying stratification.

- We were not able to explore the "tri-allelic" variation of this polymorphism.

- Since we did not have life stressors scales, we could not test the hypothesis that specific life stressors interact with this genotype to increase depression. 


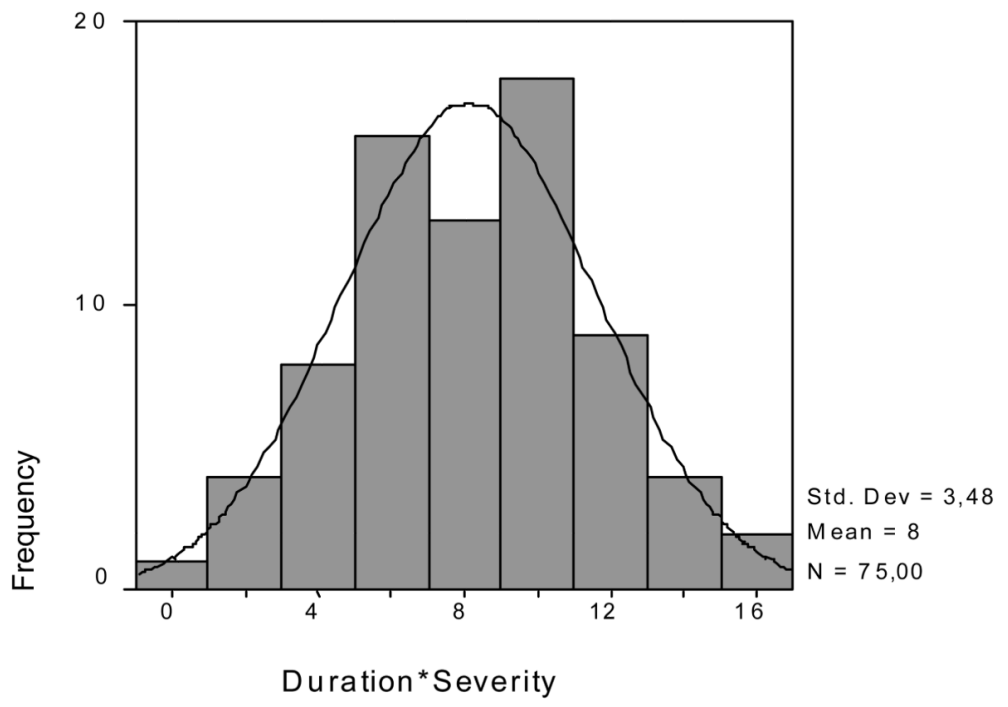

Figure 1.

Distribution (LDPS) 


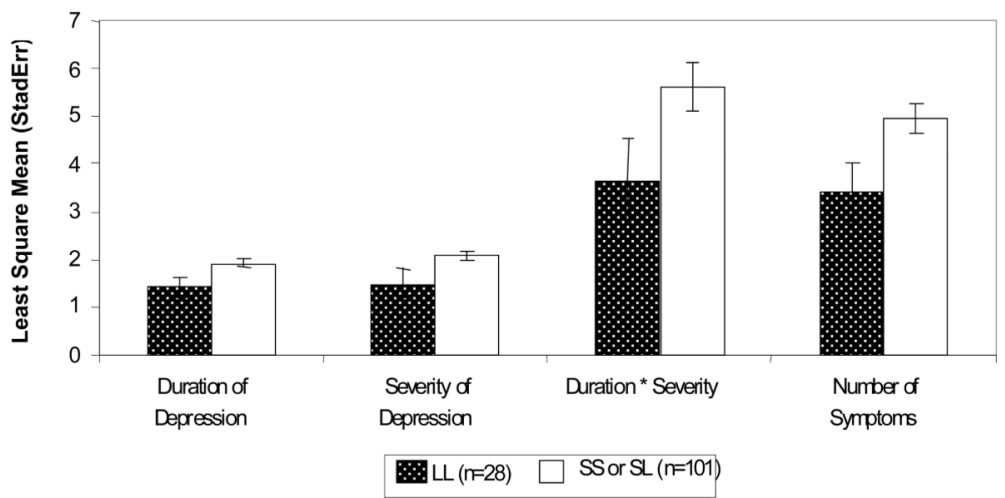

Figure 2.

LDPS least square means by genotype 


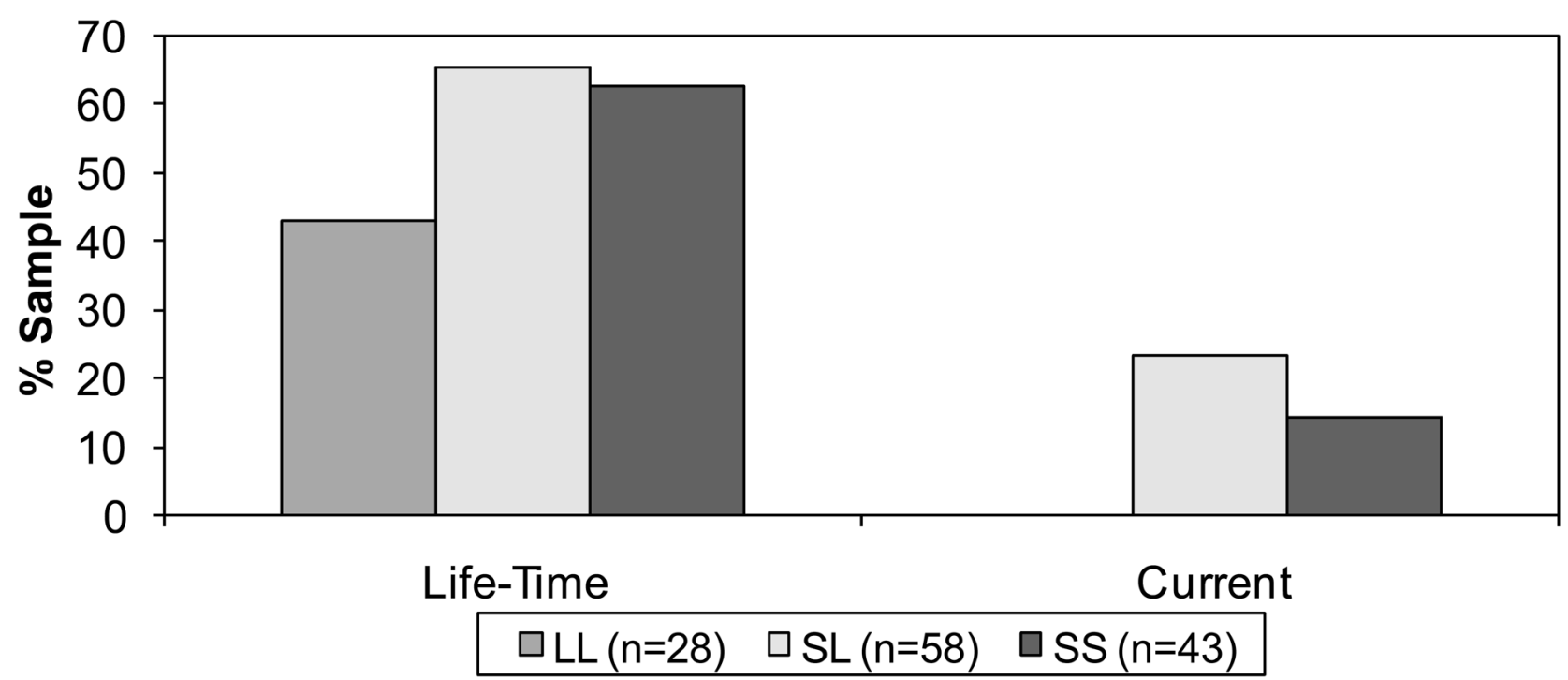

Figure 3.

Rates of Depression by Genotype 


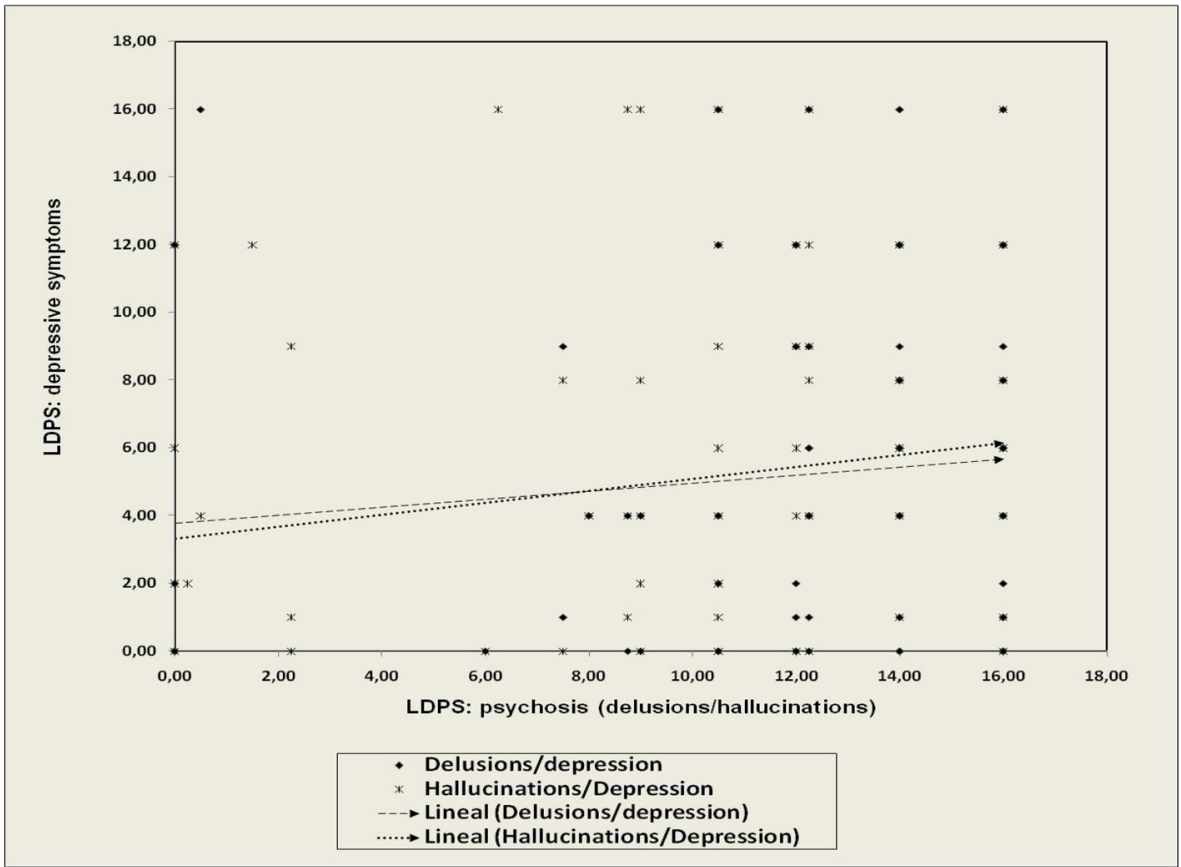

Figure 4.

Correlation between depression and psychosis in the SS/SL group. 
Table 1

Demographic and clinical characteristics of participants, by e

\begin{tabular}{|c|c|c|c|}
\hline & $\mathbf{L L}$ & SS \& SL & Statistic \\
\hline Sample Size & 28 & 101 & \\
\hline $\mathrm{Age}^{\wedge}$ & $35.21(1.7)$ & $38.08(1.1)$ & $F[1,127]=1.68, p=.197$ \\
\hline$\%$ Female & 46.43 & 39.60 & $\chi^{2}[1,127]=0.422, p=.516$ \\
\hline$\%$ Life Time Depression & 42.86 & 64.36 & $\chi^{2}[1,127]=4.211, p=.040$ \\
\hline$\%$ Current Depression & 0.00 & 19.39 & $\chi^{2}[1,127]=6.393, p=.012$ \\
\hline LDPS Duration of Depression ${ }^{\#}$ & $1.40(0.2)$ & $1.93(0.1)$ & $F[1,123]=3.92, p=.050$ \\
\hline LDPS Severity of Depression ${ }^{\#}$ & $1.49(0.3)$ & $2.08(0.1)$ & $F[1,123]=3.90, p=0.050$ \\
\hline LDPS Duration * Severity $\#$ & $3.64(0.9)$ & $5.61(0.5)$ & $F[1,123]=4.06, p=0.046$ \\
\hline LDPS Number of Symptoms $\#$ & $3.39(0.6)$ & $4.97(0.3)$ & $\mathrm{F}[1,123]=5.63, \mathrm{p}=0.019$ \\
\hline
\end{tabular}

mean (standard error);

\# least square means (standard error) while covering for age and gender 